\title{
ARTE COMO CONOCIMIENTO EN LA ESTÉTICA HERMENÉUTICA
}

\author{
M.a Carmen LOPEZ SÁENZ \\ Universidad Nacional de Educación a Distancia
}

La estética de H. G. Gadamer (1900-) no ha sido objeto de demasiados estudios en nuestro país, a pesar de su relevancia para la teoría literaria y la estética actuales. Este trabajo responde a la intención gadameriana de presentarla como parte esencial de la filosofía hermenéutica.

$\mathrm{El}$ arte, en Gadamer, es un modo de comprensión e interpretación. Por consiguiente, no es un ámbito de irracionalidad o una cuestión subjetiva dependiente de los gustos particulares o del genio, sino uno de los terrenos privilegiados de la verdad y un modo de conocimiento. En el arte opera una racionalidad distinta a la razón estratégica dominante y, por eso, el arte actúa como modelo para las ciencias humanas.

\section{La experiencia del arte como experiencia de verdad}

En la primera parte de Verdad y método, Gadamer aborda conceptos fundamentales de la estética heideggeriana, delineada en Der Ursprung des Kunwerks y de la estética hegeliana, porque la estética forma parte de la experiencia hermenéutica analizada por nuestro filósofo. Cree que la discusión estética de nuestros días no puede prescindir del aspecto hermenéutico $\mathrm{y}$, por consiguiente, "la estética debe subsumirse en la hermenéutica»1, porque el ser de la obra

1 Gadamer, H. G., Hermeneutik I. Wahrbeit und Methode. Gesammelte Werke Band I. Tübbingen, Mohr, 1960, 1965, 1972, 1975, 1981 (trad. esp. de A. Agud y Rafael de Agapito, Verdad y método, I, Salamanca, Sigueme, 1988, p. 217). 
de arte es hermenéutico, es decir, es el acontecimiento de una verdad lingüistica, la comunicación de un sentir que hay que interpretar y comprender: «La experiencia de la obra de arte implica un comprender, esto es, representa por sí misma un fenómeno hermenéutico" ${ }^{2}$. La relación con la obra es un encuentro entre dos mundos que necesitan integrarse. De este modo, la cuestión de la obra de arte es arrancada de su subjetivismo para ser aprehendida hermenéuticamente. Puesto que toda obra artística expresa el mundo del que surge, en ella hay una verdad histórica; si logramos comprenderla, avanzaremos también en nuestra autocomprensión. A pesar de sus rasgos particulares, la obra de arte pertenece al dominio de las cuestiones hermenéuticas que, al decirnos algo, nos confrontan con nosotros mismos. Esto significa que la obra enuncia algo que descubre lo escondido y es, por tanto, una verdad.

Que el arte sea comprensión y autocomprensión significa que es y requiere interpretación. Hasta la percepción estética está preñada de significado, implica la construcción de algo como algo y, por consiguiente, es un modo de comprensión y una interpretación histórica. La concepción hermenéutica de Gadamer insiste en las múltiples posibilidades históricas de los intérpretes y en la validez temporal de sus interpretaciones. La realidad de la obra de arte radica en la Sorge de los mismos. Por consiguiente, el estudio del arte y de la literatura exigen la aproximación de la filosofía hermenéutica. La conciencia estética del intérprete es también histórica y necesita autocomprenderse. En definitiva, la experiencia del arte es más que experiencia estética pura, es una forma de enriquecimiento del mundo y de nosotros mismos. Aquí tenemos una nueva versión del círculo hermenéutico (que no es en absoluto un círculo vicioso): debemos comprender el arte como fuente de verdad y al comprenderla adecuadamente nos comprendemos a nosotros mismos, pero esto sólo tiene lugar en experiencias privilegiadas como la artística; dicho con otras palabras, la persona que comprende es, a la vez, producto y condición de la comprensión. Esta circularidad pertenece a nuestro ser histórico y es, por consiguiente, ineliminable.

Gadamer sigue a Hegel al afirmar que el arte es inseparable de la historia y al establecer que la esencia del arte consiste en poner al hombre ante sí mismo; rompe con él, cuando descubre que el arte no es el paso previo para el pensamiento filosófico, sino que, en sí mismo es ya conocimiento. El arte es históri-

2 Ibid., p. 142. 
co porque una obra artística nunca se comprende de una vez por todas; cuando se la interroga no se recibe una respuesta definitiva, sino nuevas preguntas. De ahí que una obra de arte no se agote jamás. El hecho de que la obra de arte escape indefinidamente a toda explicación y oponga una resistencia insuperable a su traducción a la identidad del concepto, hace que ella represente un desafío para nuestra comprensión y demuestra que el arte puede suministrar el marco en el que se desarrolle una hermenéutica universal, porque el arte cumple la función directriz de la verdad en la multiplicidad de sus expresiones ${ }^{3}$. Por otro lado, la perspectiva hermenéutica es universal porque incluye tanto la experiencia de lo bello en la naturaleza, como en el arte. Este pertenece al proceso íntegro de la vida humana situada en las tradiciones (éstas no incluyen sólo los textos, sino también instituciones y formas de vida). Ahora bien, la obra de arte no es tan sólo un legado del pasado, sino que posee una actualidad particular debido a que está siempre indefinidamente abierta a nuevas integraciones; dicho de otro modo, la obra de arte posee una presencia que va más allá del presente. Esto no significa, sin embargo, que el arte sea autosuficiente o que no requiera interpretación. Ahora bien, la interpretación del arte no es una mera interpretación histórica. La obra de arte dice algo a alguien, pero no de la misma forma que un documento histórico; lo dice a cada uno como si fuera único, como si se tratara de un fenómeno contemporáneo que contiene todavía la verdad.

Si esto es así, el sentido del arte no se agota en una visión subjetiva de la realidad. Para demostrarlo, Gadamer, en la primera parte de Verdad y método, intenta elucidar la cuestión de la verdad desde la experiencia de la obra de arte. Anuncia que el arte contiene y trasmite la verdad. Con objeto de descubrir las características de la verdad propia del arte, este filósofo emprende una fenomenología de la experiencia de la misma.

Como Hegel, Gadamer piensa que el arte representa la manifestación sensible de la idea. Frente a él, no subordina la verdad del arte a otra superior, sino que la considera arquetípica con respecto a las restantes verdades que se dan en las ciencias del espíritu. En éstas, lo primario no es el objeto ni el sujeto, sino la correlación entre ambos de la que arranca la "objetividad" propia de estas

3 Cfr. GadAMER, H. G., Hermeneutik II. Wabrbeit und Methode. Gesammelte Werke II. Tübingen, Mohr, 1986 (trad esp. de M. Olasagasti, Verdad y Método, II, Salamanca, Sígueme, 1992, p. 15). 
ciencias. Gadamer toma como ejemplo de las mismas la obra de arte, porque es representación u objetividad que incluye la mediación de un sujeto; es decir, la obra de arte no es un simple objeto, sino una experiencia que transforma al que la experimenta. La subjetividad que está aquí en juego es una subjetividad ampliada, porque no es sólo la del autor, sino también la del receptor y la de la transmisión. Del mismo modo, la objetividad de las ciencias del espíritu hay que buscarla no sólo en los datos que éstas nos ofrecen, sino también en el sujeto y en la tradición, es decir, en la comunidad de sentido a la que pertenecemos cuando interpretamos.

Gadamer entiende así la experiencia estética como un tipo de experiencia histórica, ya que ambas envuelven una mediación de significado con nuestra propia situación o una fusión del horizonte del pasado (objeto) con el del presente (sujeto). Admitir que en el arte hay experiencia de verdad y que ésta exige ser interpretada significa entender la interpretación como reunión del objeto y del sujeto. El objetivismo y el metodologicismo que guía a la ciencia es incapaz de aprehender esa verdad relacional; es más, el interés por el método aleja al cientificismo de la preocupación por la verdad. El arte, en cambio, no necesita rendirse ante el método, porque no necesita demostraciones, ya que es un modo de verdad anterior a ésta.

La experiencia del arte se caracteriza porque la obra posee siempre su propio presente y expresa una verdad irreductible tanto al objeto apuntado como a la intención de su autor. La obra de arte ni es un objeto ni gusta como si lo fuera; no se reduce a algo decorativo, sino que se desarrolla en el curso de su existencia provocando placer y aversión. Cuando apreciamos algo en función de su calidad estética, nos alejamos de los entes que nos son familiares; dicha distanciación es lo que posibilita el juicio estético y surge cuando nos sustraemos a la llamada inmediata de lo que nos aprehende. De ahí que Gadamer proclame la soberanía de la estética que se afirma en la experiencia del arte y conciba ésta como la auténtica realidad.

La experiencia artística constituye una alienación por distanciación; es decir, cuando apreciamos algo en función de sus cualidades estéticas, se produce un distanciamiento de lo familiar; esta distanciación hace posible el juicio estético.

Gadamer se centra en la experiencia del arte porque, aunque ella es conocimiento e incluso autoconocimiento, su sentido no se agota en la comprensión conceptual; en todo caso, «la expresión que convendría al objeto de una estéti- 
ca que desea ser teoría del arte sería la de cognitio imaginativas ${ }^{4}$. El arte es intuición o visión del mundo. Esto significa que, frente a la ciencia, el arte cobija una verdad propia, en la medida en que el libre juego de la imaginación se encamina al conocimiento; además la intuición interior nos muestra la totalidad del ser en el mundo. La determinación propia del arte no es, por tanto, la conceptual, sino esa corriente de intuiciones internas en las que se construye la contemplación a la que nos constriñe. La experiencia de la obra de arte no es obra del entendimiento o de la sensibilidad tomados aisladamente, sino que se produce en la unidad y en la continuidad de nuestra autocomprensión. La obra no nos presenta una copia de la realidad, sino que nos dice lo que es capturando la realidad en una imagen. Gadamer abandona las características representacionales de la obra de arte, porque, aunque reconoce que ésta no es ajena a la verdad, sabe que la verdad no está determinada de una vez por todas y que también el arte puede contribuir a desvelarla. Por eso, cuando comprendemos una obra de arte, no comprendemos su verdad como una representación inmodificable de lo que realmente es el objeto dado, sino desde nuestro punto de vista. En otras palabras, Gadamer concibe el arte como transmutación en la verdad de la experiencia ordinaria. Esto parece indicar que Gadamer se inspira en las manifestaciones artísticas clásicas y relega el arte abstracto carente de contenido cognoscitivo a la Erlebniskunst. Sin embargo, Gadamer nunca ha afirmado esto, es más, ha insistido en que la verdad del arte no pertenece a la conciencia, sino a la inversa, porque lo verdadero no es una posesión de la conciencia, sino el acontecimiento al que pertenecemos. De ahí que diferentes interpretaciones de una obra puedan ser verdaderas sin por ello desintegrarla. Gadamer diría que la incomprensibilidad del arte moderno no se opone a su teoría estética, sino que refleja la opacidad del mundo actual, porque el enmudecimiento de la imagen también es una manera de comunicar la verdad de nuestro mundo desmembrado. En suma, la renuncia del arte moderno al significado es ella misma significativa, del mismo modo que la aparente carencia de ideología es una nueva construcción ideológica. En la discontinuidad del arte moderno se asienta la continuidad con nosotros mismos, la idea de que el acontecer de la verdad en el arte sigue siendo una tarea de comprensión. En este sentido, Gadamer concede una clara primacía a la com-

4 Gadamer, H. G., «Anschauung und Anschaulichkeit», Neue Hefte für Philosophie, Heft 18/19, pp. 1-14 (trad. esp. de A. Gómez, "Intuición e intuitividad", Estética y hermenéutica, Madrid, Tecnos, 1996, p. 157). 
prensión y a la mimesis. Así subraya la función integradora del arte que se transciende abriéndose a otras dimensiones.

\section{El arte como modo de ser y de conocer la realidad}

Para describir la relación entre la obra de arte y la realidad, Gadamer retoma el concepto de mímesis, abandonado tras el triunfo de la estética del genio y de la mentalidad científica, para las cuales la imitación denotaba falta de originalidad y de exactitud, respectivamente. En Gadamer, por el contrario, la mimesis define el status ontológico de la obra de arte. Adopta el término tal y como es definido por Aristóteles, no como copia o reproducción de la realidad, sino como transposición de ésta en su verdad. En la imitación artística no se refleja planamente lo exterior, sino que las formas se instituyen en totalidades de significado y la realidad se manifiesta tal y como es. Para demostrarlo, Gadamer analiza la problemática de la pintura originaria y de la copia. Concibe el arte como Darstellung o presentación; ésta no tiene por qué ser siempre una copia, ya que incluso en las reproducciones se reconoce el original y, por tanto, a diferencia de la imagen especular, que no tiene ser real, la imagen estética tiene su ser propio como presentación, es decir, tiene realidad per se, puesto que cada presentación es un acontecimiento del ser. Así pues, hay relación ontológica entre la imagen originaria y la copia. Gadamer afirma que la manera de ser de esta relación es la representación. Ahora bien, "representar" tiene, en Gadamer, un significado fenomenológico, es decir, "representación" no es un contenido de la conciencia, sino un modo de presentación del mundo; "representar» no es reproducir algo, sino presentarlo de una nueva manera, produciendo determinados efectos en el original: éste sólo es tal gracias a su representación. Lo presentado logra, gracias a la imagen, una nueva aparición más verdadera. Palabra e imagen son acontecimientos del ser y en ellas aparece éste de forma plena y con sentido. La presencia de la imagen no es ni una pura referencia ni una pura sustitución. Análogamente, la hermenéutica no es restauración o restitución de la vida pasada, sino —como decía Hegel— mediación reflexiva de la vida presente.

El original (Urbild) está constituido como tal por la imagen (Bild) en el sentido de que sólo se ilumina en las imágenes que el arte nos da de ella. Una imagen (Bild) no es una reproducción o una imitación de una idea, sino que la idea se expresa a sí misma y cobra realidad en la obra de arte. En la imagen el ser ac- 
cede a una manifestación visible y con sentido. Así, por ejemplo, la pintura no copia el mundo real, sino que es el mismo mundo con un sentido intensificado. Gadamer piensa que el original puede ser representado precisamente porque es una imagen. La pintura no es mero reflejo, ya que no depende de la presencia del original, sino que existe por sí misma y ella misma significa. La obra de arte es identidad separada, mantiene una relación metafórica con el original; al mismo tiempo es independiente de éste, por su indispensabilidad, porque hay algo en el original que sólo es descubierto mirando la obra de arte. El original posee posibilidades alternativas de autopresentación y, por eso, es independiente de la obra; siempre se presenta como algo y, por tanto, depende de la obra; a la vez, ésta lo representa. Esta interdependencia dialéctica demuestra que el original tiene una existencia más plena, pero gracias al arte se auto-representa. La autonomía del original radica en que tiene múltiples alternativas de auto-representación, pero siempre depende de sus representaciones como éstas de él. El ser, como el arte, surge cuando el original se fecunda y emana en el ser autónomo de la obra, en suma, cuando el original se origina, se constituye como algo. Dicho de otro modo, el arte imita la naturaleza y ésta no es sino lo que el arte imita. La obra es, pues, una interpretación del mundo y por el mundo. Ahora bien, ¿cómo pueden los múltiples mundos artísticos convertirse en uno? En su intento de respetar la identidad y las diferencias, Gadamer responde que el arte tiene una función mediadora y que cada universo artístico preserva algo del viejo mundo alterándolo; es decir, prevalece la dialéctica gadameriana entre la familiaridad y la extrañeza, entre la identidad y la diferencia.

Estas consideraciones ilustran la concepción gadameriana del arte como Darstellung. la obra no sólo representa la realidad, sino que la ejecuta haciéndola presente e interpretándola. Toda presentación es representación para alguien y a través de alguien, es un acto interpretativo históricamente determinado y sólo en la interpretación la obra se revela en su realidad autónoma. Al no darse sino en su ejecución, la obra es temporal porque está hecha para ser ejecutada; goza de infinitud y transciende la conciencia y las intenciones del autor. La infinitud de la obra consiste justamente en su historicidad y eventualidad, por las cuales el autor la introduce en un juego que él no puede controlar y en el que la obra cobra vida propia. Del mismo modo, la verdad del arte no es sino el acontecer de la verdad, una producción histórica con un significado y una consistencia que se presenta en otros acontecimientos históricos que son las interpretaciones y que plantea por tanto el problema de la mediación entre estos mundos distintos, el problema hermenéutico. 
Ahora bien, Gadamer no se contenta con afirmar la temporalidad del arte o de la interpretación y la pluralidad de sus manifestaciones, sino que además se pregunta por la verdad que subyace en ellas 5 . La experiencia de una obra de arte nos abre nuevos mundos, porque el arte no es sólo percepción de lo fáctico, sino también creación y conocimiento. Los objetos cotidianos aparecen iluminados por una luz nueva cuando son transformados por el arte. La legitimación del arte no radica, por tanto, únicamente en el placer estético que produce, sino en su revelación del ser. La fusión de la verdad o del ser representado con la forma artística es tan completa que algo nuevo llega, con ella, al ser. Por eso la obra significa totalmente, no es ni contenido ni forma que se añadan a algo ya dado.

En Gadamer, el conocimiento propio del arte está relacionado con la rehabilitación del concepto de mímesis. La mímesis artística no es simple imitación, sino interpretación de la cosa, proceso creativo. Mímesis es, en Gadamer, conocimiento: la representación artística hace que surja algo de la realidad que antes no era visible y, por tanto, abre su esencia; en este sentido, mimesis es reproducción esencial o presentación de la esencia, un acontecimiento ontológico. El original no tiene una naturaleza acabada, sino que continúa deviniendo gracias a sus representaciones. Los originales son de alguna manera ya, en sí mismos, miméticos. Sin la mímesis de la obra, el mundo no estaría allí. La verdad de la obra posee realidad propia gracias a la participación histórica del intérprete. La insistencia gadameriana en el hecho de que en toda expresión artística se halla inscrito lo expresado mismo, tiene como consecuencia que toda posición hermenéutica que vea en la obra el síntoma de algo que no aparece sea rechazada.

Mediante el concepto de mimesis, Gadamer quiere comprender los dos momentos fundamentales de la experiencia estética: la relación de la obra con el original y la relación con sus interpretaciones. Se trata de una doble mimesis. Ahora bien, si en Platón la obra de arte era imitación de una imitación, en Gadamer es realidad auténtica, porque no es mera copia, sino conocimiento de la esencia. Gadamer cree que en la representación mimética, la cosa emerge en su verdadero ser, sin necesidad de reenviar a lo originario. Toda representación es un acontecimiento ontológico, o sea, constituye el estado ontológico de lo representado; en ella, aumenta el ser de éste. Por tanto, la interpretación interviene necesariamente en la obra; en la interpretación se manifiesta la infinitud

5 Cfr. Gadamer, H. G., Verdad y Método, I, p. 222. 
de la obra que va más allá de las intenciones del autor, porque aquélla no es un en-sí, porque su identidad es dinámica, se abre al futuro. Esto no implica que haya de ser sustituida por sus interpretaciones, sino que todas son contemporáneas suyas. Dicha contemporaneidad no ha de entenderse como eternidad, sino como plena presencialidad; lo que posibilita esa contemporaneidad es la conciencia histórica. Desde esta perspectiva, ¿cómo se puede concebir la identidad de la obra en sus múltiples interpretaciones históricas? Gadamer responde nuevamente con la categoría de "contemporaneidad": todos los aspectos que la obra asume en las interpretaciones son contemporáneos de su identidad.

Al subrayar la función cognoscitiva del arte, Gadamer denuncia la estetización de los conceptos cardinales del humanismo, especialmente del juicio y del gusto. Cuando a éstos se les negó la función de conocimiento que siempre habían tenido, se desacreditó el saber teórico de las ciencias humanas por considerar que no satisfacía los criterios de las ciencias exactas. Gadamer acusa a Kant de iniciar este movimiento que obligó a las ciencias humanas a definir su cientificidad según el modelo alienante de las ciencias puras. Intenta mostrar que esa concepción de la conciencia estética es una falsa abstracción que proviene de la banalización impuesta por la ciencia moderna a todo aquello que no se corresponde con sus normas de conocimiento. En este sentido, Gadamer se opone a la subjetivización kantiana del juicio estético que ha conducido a entenderlo como expresión de las preferencias personales y a aislarlo de la verdad. En efecto, para Kant, los juicios de gusto y de belleza no eran resultado de actos de reflexión o conceptualización y, por tanto, los juicios morales no podían basarse en ellos. Tomó como modelo de belleza la naturaleza que se presentaba de forma inmediata, sin conceptos, que daba placer por sí misma sin apelar a nuestros propósitos. Por otro lado, Kant basaba la universalidad del placer estético en el a priori de belleza ideal, que era la presencia en forma sensible del libre juego de la imaginación. Su filosofía del arte lograba la intersubjetividad al precio de renunciar a la justificación conceptual. Según Gadamer, la fundación transcendental kantiana del juicio estético en el concepto de gusto, sirve para reivindicar la validez universal y autónoma de éste, pero le priva de todo alcance cognoscitivo y de toda pretensión de verdad. Aunque, en Kant, la obra de arte todavía no incurría en el subjetivismo absoluto, ya que representaba la unión de naturaleza y libertad, Gadamer observa que esta concepción reduce la obra artística a una pura representación exenta de producción. Según nuestro filósofo, en cambio, el juicio de gusto es un tipo de conocimiento no metódi- 
co ni demostrativo, pero en él lo universal es determinado productivamente por lo particular y tiene un alcance cognoscitivo; no es, por tanto, meramente subjetivo, sino que expresa el «sensus communis» o la voluntad profunda de una comunidad.

La intuición kantiana del papel del genio todavía separó más el arte del conocimiento. El genio kantiano era capaz de representar el libre juego de las fuerzas naturales. A diferencia de la belleza natural, la artística era, en Kant, un producto del genio. Éste era el origen de la idea estética, que iba más allá de los límites del concepto poniendo en movimiento el libre juego de la imaginación y del intelecto. La obra de arte bella era, entonces, la unión del gusto y del genio. De este modo, Kant ponía las bases de la estética idealista. Según Gadamer, el concepto kantiano de genio está en la raíz de la doctrina neokantiana de la vivencia, según la cual la obra de arte muestra los sentimientos del artista. Gadamer se opone a la alianza entre vivencia y símbolo, porque aquélla supone reducir la validez del objeto a la subjetividad transcendental. De este modo, se impone la concepción del mundo del arte como mundo de la apariencia contrapuesto al mundo real, esto es, la diferenciación estética, que surge como fruto de una abstracción por la que la obra asume existencia autónoma y la conciencia soberana establece lo que ha de considerarse estético. El concepto de conciencia abstracta que subyace en el pensamiento estético de Kant supone que el sujeto mira una obra de arte como si se tratara de un objeto de estudio. En cambio, Gadamer sostiene que esta distancia es ficticia, pues sujeto y obra se modifican al encontrarse. Por eso se propone reconducir la creatividad del genio al encuentro productivo con la obra y el intérprete. En el juego del arte se transmuta la realidad, en tanto que es aprehendida en su idealidad y perfección. Así, en Gadamer, la obra de arte no está al margen de la existencia ordinaria, porque no es el producto de un genio, sino transmutación de la realidad en su verdadero ser, lejos de las pasiones de la existencia finita. Por eso, en el encuentro con la producción artística, se realiza la auténtica liberación y el verdadero cumplimiento. Estos resultados no son atribuibles al artista, sino al acontecimiento en el que éste participa, pero que lo transciende.

Gadamer está de acuerdo con Kant en que el arte es símbolo y, por tanto, no puede reducirse al concepto; no discute que el arte sea función de la subjetividad y del juicio estético, pero asegura que es más que esto, porque el símbolo siempre significa más de lo que es. Paralelamente, en opinión de Gadamer, aunque el conocimiento estético es diferente del conocimiento sensorial de la 
ciencia y de todo conocimiento conceptual, sigue siendo conocimiento, es decir, «mediación de verdad»6.

Gadamer acusa a Kant de haberse dejado llevar por el criterio científico natural y de situar al margen de éste los juicios reflexivos, a los que pertenecen los juicios estéticos; le acusa también de haber subjetivado a éstos últimos. Antes de Kant, en cambio, el concepto de gusto era más moral que estético porque describía un ideal auténtico de humanidad. Gadamer desea recuperar ese ideal: la complementariedad de lo bello natural y artístico con lo bello de la realidad moral. Al separar ambas realidades, Kant cerró el camino de la verdad para las ciencias del espíritu y contribuyó a la pérdida de la legitimidad de éstas ${ }^{7}$. Los conceptos de conocimiento, verdad y método utilizados por Kant están en la base de los actuales postulados científicos y deben ponerse en tela de juicio si queremos que las ciencias del espíritu sean también conocimiento.

La subjetivización kantiana de la estética ha conducido a la completa estetización del arte, lo cual significa, siguiendo a Gadamer, la disolución del arte mismo y de su relación con el conocimiento, porque ahora ya no importa si el objeto del arte es real o no, ni el fin último al que ésta se dirige. Esto ha desencadenado la crisis de la conciencia estética como resultado de toda la historia de la estética postkantiana, la cual disolvió los contenidos ontológicos que, todavía en Kant, limitaban el significado subjetivo de la separación establecida en la Critica del juicio entre el gusto y la facultad cognoscitiva. Como hace notar Vattimo, esta actitud ha conducido al aislamiento del arte de la naturaleza: "Con la decadencia, por problemática que sea, de toda visión teleológica de la naturaleza, la autonomía del arte se asemeja cada vez más a una evanescente experiencia sin raíces ontológicas»"8.

Gadamer va más lejos y critica la estetización que se ha producido con todo lo que se declara independiente de la ciencia y esto le lleva a cuestionarse la autonomía del arte en nuestras sociedades. El filósofo no está a favor de dicha autonomía, porque el modo específico de la obra de arte es corresponder a la representación del ser y no podemos comprender el arte tan sólo como objeto o producto de la experiencia estética, no podemos considerarlo solamente como arte.

6 Cfr. Vattimo, G., Poesia y ontologia, Valencia, Murcia, 1993, p. 157.

7 Cfr. Gadamer, H. G., Verdad y Método, I, p. 74.

8 VATtimo, G., op. cit., p. 176. 
La progresiva estetización de la experiencia artística culmina con la crisis del concepto de "genio", entendido como producción inconsciente que se desvanece en el siglo $\mathrm{xx}$, perdiéndose toda la consistencia individual de la obra que queda reducida a mero correlato de Erlebnisse discontinuos que constituyen la conciencia estética. Gadamer reacciona a esta tendencia transformando la estética en hermenéutica, porque está convencido de que la relación con la obra es encuentro con una verdad dada como acontecimiento histórico que exige ser comprendida en un acto que, a su vez, se autocomprende. En el mundo nos encontramos con la obra de arte y en ésta nos encontramos con un mundo. La obra de arte tiene su origen en el tiempo, pero cuando se libera de su creador, se distancia del momento histórico en el que surgió para instalarse en la intemporalidad. Eso permite comprender la obra desde la historicidad y, en tanto que inscrita en la intemporalidad, evita que el intérprete deje en suspenso su propio horizonte.

\section{El «juego» en la representación artística}

A pesar de que el libre juego de las facultades marca, en el ámbito estético, una relación del sentimiento de gusto con el conocimiento, no cabe duda de que Gadamer tiene razón cuando entiende la belleza kantiana como un sentimiento subjetivo y no como un conocimiento. En contra de Kant, hemos visto que Gadamer piensa que la experiencia estética tiene cierta objetividad y, para confirmar su tesis, adopta el concepto kantiano de juego, pero reformulándolo.

Gadamer equipara el juego con la representación artística y con la interpretación hermenéutica. La esencia del juego es la representación, aunque jugar es también jugarse, es decir, auto-representarse. Como hemos visto, niega que la representación sea una mera copia y la define como el salir a la luz lo representado. El ser se actualiza en cada representación y no existe al margen de ésta; paralelamente, no hay representación que no desarrolle y vivifique lo representado. Spiel es juego y representación en este sentido o, mejor dicho, construcción (Gebilde) con sentido en orden a la representación. Del mismo modo que la obra de arte es lo que perdura y no la subjetividad del creador o de quien la experimenta, el juego tiene una esencia independiente de la conciencia de los jugadores, se juega a través de ellos y saca a la luz una verdad que está más allá de los mismos: la cosa misma, lo que siempre es. La verdad es la cosa misma 
que vive en el juego de las representaciones o interpretaciones; en ellas, se nos presenta lo subjetivo referido a lo objetivo de manera indivisa. El que representa desarrolla dinámicamente lo representado, que, por otro lado, sólo es aprehensible en la representación. Gadamer lleva a cabo una re-evaluación ontológica del juego subrayando su carácter representativo de lo verdadero: los mundos «irreales" del arte y del juego son la verdadera realidad, porque tienen más ser que lo real-cotidiano. La concepción del juego como representación se opone a la contraposición neokantiana de fenómeno y cosa en sí y en general a la contraposición entre ser y pensar propia de toda la filosofía tradicional. Frente a ella, Gadamer pretende hacer una descripción fenomenológica de la esencia del juego en tanto fenómeno en el que se manifiesta la esencia de la cosa; para ello, se distancia de la conciencia del jugador que comprende la estructura del juego sólo a partir de su aparición subjetiva. Considera que el juego muestra el modo de conocimiento y de verdad del arte, siempre que esté liberado de las connotaciones subjetivas que tiene en Kant o Schiller. El juego pertenece a la constitución ontológica del ser humano, no es, por tanto, un fenómeno marginal. Carece de meta última, pero tiene fines, lo que ocurre es que éstos son inmanentes al juego mismo.

El juego es un movimiento que comprende a los que juegan (sujetos) y al juego mismo (objeto). Tiene dinámica propia y por eso es incierto, es un riesgo para el que juega, un auto-representarse. El juego es pura autopresentación, ya que en él los jugadores se identifican completamente con la acción. A pesar de eso, no carece de jugadores, sino que, en él, el sujeto se transforma en el encuentro con los otros; el juego es un intercambio cuyo resultado es la comprensión, la interacción con algo que es aceptado como verdad. En el juego, no hay contraposición entre el jugador y lo jugado, sujeto y objeto, realidad y conciencia. Como el ser, el juego es movimiento que comprende a ambos y los hace interdependientes: la conciencia se va formando con la experiencia de lo real y éste es configurado por aquélla. La obra de arte, como juego, es algo dinámico que elude la contraposición clásica entre sujeto y objeto; su verdadero ser es su conversión en experiencia y su transformación de la misma.

El juego no sólo define la esencia de la obra de arte, sino también la de la interpretación: ambas son ex-posición, auto-representación; en ellas no existe contraposición entre sujeto y objeto; de ahí que todo jugar sea un ser jugado, pues es el juego el que juega y no nosotros. Si en el juego el ser se revela a sí mismo, en el juego ideal que la obra de arte instituye se realiza la transformación de la realidad en su verdad, porque aquélla auto-expone su propio mundo 
poniendo en juego la pluralidad de sus aspectos reales. El juego instaurado por la obra de arte se evade de la finitud descubriendo una presencia intemporal y jugar es, como interpretar, tomar parte en la comprensión que toda obra instituye, dejar ser a lo que es, pero dejar ser no significa sólo repetir lo que ya se sabe, sino comprender el fluir, la conformación permanente y duradera de las cosas y de nosotros mismos. No es extraño, entonces, que Gadamer denomine a su teoría del arte «ontología de la obra de arte» y que siga el modelo del juego y el principio de la primacía de éste sobre la conciencia de los jugadores. El concepto de "juego" deriva en Gadamer del concepto heideggeriano de «verdad". Antes de Gadamer, otros autores han concedido una importante relevancia a dicho concepto. Así Schiller manifestaba que el ser humano era completamente humano sólo cuando jugaba ${ }^{9}$. Gadamer quiere corregir la inclinación antropológica y subjetivista de Schiller y, para ello, relaciona el juego con la experiencia del arte. Como ésta, el juego no hace referencia ni a la actitud ni al estado del espíritu del creador, ni al placer ni a la libertad de la subjetividad, sino al modo de ser de la misma obra. De forma análoga a ésta, el juego tiene su modo primario de existencia en la presentación. Schiller separaba el arte de la realidad; según Gadamer, éste no es el sentido originario del arte, el cual completa a la naturaleza y, como ella, no cumple un propósito, porque la naturaleza misma es un juego que siempre se renueva, sin intención predeterminada y, por tanto, es el modelo del arte. Juego y obra artística transforman a quien los experimenta. El estatuto ontológico del arte radica en que aniade algo a la experiencia, es una forma de lenguaje que incluye idealización. La idealidad de la obra no se determina por su referencia a una idea que sirva de modelo, sino como el aparecer de la idea misma, como ocurre en Hegel. Símbolo y juego aplicados al arte son auto-representaciones del ser. La condición representativa-presentativa del ser al que accedemos a través del arte es una estructura ontológica universal que se realiza en el lenguaje.

La manera de ser del arte es el juego, el cual sólo existe cuando es jugado. Del mismo modo, la obra de arte no se diferencia de su representación, sino que existe en ella. Si la obra de arte es esencialmente su propia representación y, puesto que las posibilidades de representación están aún abiertas, el sentido de la obra no está determinado mientras no lo esté la historia; de tal manera que a su esencia pertenece constitutivamente la temporalidad. La temporalidad es-

9 Cfr. SCHILLER, F., Cartas sobre la educación estetica del hombre, Barcelona, Anthropos, 1990. Carta 15. 
pecífica del ser estético consiste en que tiene su ser en el representarse. La presencia específica de la obra de arte es un acceso-a-la-representación del ser.

La relación de pertenencia del intérprete a la obra de arte como Spieh además de ser el modelo de relación de pertenencia del hombre a la historia, se convierte en paradigma de la relación misma con el ser, y por eso Gadamer habla, en la parte final de Verdad y Método de una "ontología hermenéutica". Ahora bien, el ser del arte no puede determinarse subjetivamente, como si fuera el objeto de una conciencia estética, porque el comportamiento estético es más de lo que él sabe de sí mismo; es parte del proceso óntico de la representación y pertenece al juego como tal. Arte y juego no son objetos controlables por un sujeto y esto es lo que nos fascina de ellos, su autonomía. Para jugar hay que implicarse en el juego, porque éste sólo existe en su ejecución. El juego no es una respuesta subjetiva, no es la satisfacción de la necesidad de jugar, sino una construcción, un todo significativo que revela la actividad lúdica o el movimiento de vaivén que incluye su propio fin. Todo porqué desaparece en el juego, ya que su experiencia es anterior a las normas y a los métodos. En el juego se experimenta la verdadera libertad, el abandono completo a unas reglas independientes del mundo ordinario, la vida que transciende al jugador. El juego se transmuta en arte cuando se produce la Verwandlung ins Gebilde, la transformación de lo real en la verdad acrecentada de su ser, gracias a la imbricación ontológica del ser original y del reproductivo. La transmutación en forma indica la transcendencia de la obra respecto al mundo cotidiano; ser forma quiere decir que la obra ha encontrado en sí misma su propia medida y no se confronta con nada externo. La forma de la obra de arte es una totalidad significativa, por tanto, no puede escindirse de sus ejecuciones o interpretaciones.

La diferencia entre el juego del arte y los otros juegos es esta transmutación en forma. Mediante ella, la obra asume la consistencia de un objeto que puede ser siempre jugado de nuevo con una autonomía de la que carecen otros juegos. En el arte se produce esta transmutación porque, en ella, la transcendencia del juego con respecto a los jugadores ha adquirido la consistencia de un objeto, que se propone ejemplarmente a la fruición, a ser jugado continuamente pero con una autonomía de la que carecen las simples reglas de los juegos comunes. La obra como Gebilde realiza también la esencia del juego que es Selbstdarstellung o autorrepresentación: el juego es por esencia una manifestación de sí en el jugar de los jugadores, que son, en cierto modo, medios de esa manifestación. La obra misma es captada y gozada como realidad. La diferencia entre obra de arte y realidad estriba en que ésta se nos da en la experiencia coti- 
diana y aquélla constituye una totalidad de significado más precisa, opuesta al caos de posibilidades no realizadas de que está hecha la vida común.

\section{La revalorización del receptor}

La crítica gadameriana de la estética del genio y de la intención autorial, ha conducido a la revalorización del mensaje artístico (función de conocimiento del arte) y del receptor (función de autoconocimiento); asimismo, el carácter dialéctico que Gadamer atribuye al arte lo acerca al paradigma del diálogo y la conversación. Esto indica que Gadamer no concibe una dimensión puramente estética del arte. Se opone al purismo estético porque piensa que toda obra de arte es interpretación, mímesis o comprensión de lo que no es arte, gracias a su representación.

Frente a él, H. R. Jauss rehabilita el gozo artístico y se opone a la unilateralidad y desvalorización que de él ha hecho la estética gadameriana ${ }^{10}$. Sin embargo, ésta no es la verdadera intención de Gadamer, pues si bien renuncia a la autonomía intranscendente del arte, al mismo tiempo rechaza la subordinación de ésta a los conceptos filosóficos y, en suma, la heteronomía del arte.

A pesar de sus críticas a Gadamer, Jauss se inscribe en la estética de la recepción, que sigue, en lo fundamental, las convicciones estéticas de éste. Con el nombre de "estética de la recepción" se caracteriza una teoría literaria que tiene como tema fundamental los modos y resultados del encuentro de la obra y su destinatario. Dentro de esta orientación podríamos incluir, además de a Jauss, a R. Ingarden, W. Iser, S. Fish, etc.

Jauss considera que el sentido de una obra no está previamente determinado, sino que se constituye en la recepción de la misma. Este autor se opone a la reducción de la realidad a un conjunto de esencias pretendidamente eternas. Reconoce que la historia de la literatura ha sido generalmente una historia de los autores y obras y ha obviado al lector, al espectador o al auditorio. Se ha eludido hablar de la función histórica del destinatario, cuando lo cierto es que la literatura y el arte se convierten en procesos historicos gracias a él y a su progresiva construcción de una tradición o de una respuesta a la misma (papel pa-

10 Cfr. Jauss, H. R., Negativität und Identifikation, VI, München, Weinrich, 1975, pp. 263-339. 
sivo y activo respectivamente del destinatario). La atención que Jauss presta al destinatario que actualiza las obras puede ponerse en relación con los estudios de Aristóteles o Kant sobre los efectos del arte en el público. El destinatario tiene la función de discriminar y de reinterpretar las obras recibidas. Ahora bien, Gadamer seguramente se preguntaría si el estudio de éste no nos aboca al psicologismo o al sociologismo. La respuesta de Jauss, siguiendo de nuevo a Gadamer, sería que la recepción de una obra no se reduce a la simple sucesión de impresiones subjetivas o colectivas, sino que es una percepción guiada por los signos del texto. Gadamer añadiría que si la experiencia de la obra de arte transciende el horizonte subjetivo de interpretación del artista y del perceptor, lo decisivo para comprenderla no será ni la intención de aquél, ni la interpretación de la obra al margen de la historia; no bastará recurrir a la mens auctoris, ni a la subjetividad de la opinión. El significado de la obra de arte es compartido por el creador y la audiencia, porque toda obra de arte incluye ya en sí misma una necesidad de interpretación o de participación en su significado.

El público asume, para Jauss, el papel de mediador en el plano sincrónico (hace de intermediario entre vida y literatura) y en el plano diacrónico (encadena textos antiguos y nuevos). En definitiva, la estética de Jauss analiza la relación entre producción, representación y recepción y considera que toda reproducción del pasado artístico es parcial. Lo que persigue, en suma, es devolver al arte actual la función comunicativa que prácticamente ha perdido ${ }^{11}$. Su objeto, pues, se identifica con el de Gadamer, ya que éste estudia la obra de arte como lugar de la verdad y ésta es irreductible a la oposición entre sujeto y objeto y aprehensible tan sólo de manera comprensiva y dialógica.

Jauss se vincula explícitamente a Gadamer defendiendo una refundación hermenéutica de la historia de la literatura. Este autor subordina el concepto de historia de la recepción al de historia de los efectos, entendiendo el efecto de una obra en dependencia de la participación activa del receptor. Comprender no es, para él, insertarse en el acontecer de la tradición, sino apropiarse activamente de la obra por mediación de las aproximaciones anteriores que constituyen la historia de su recepción.

A la fusión diacrónica de horizontes gadameriana, Jauss añade una fusión sincrónica y la reformula en lo que él llama "horizonte de expectativas" u horizonte de reglas de los textos que le han precedido; un horizonte que será mo-

11 Cfr. Jauss, H. R., Pour une esthétique de la réception, Paris, Gallimard, 1994, p. 262. 
dificado o simplemente reproducido tras la lectura y el reconocimiento de ese marco trans-subjetivo de comprensión que condiciona el efecto del texto. Jauss se está refiriendo (prioritariamente, aunque no exclusivamente) a la experiencia directa del lector "ordinario" que precede a la experiencia reflexiva posterior. El «horizonte de expectativas» juega un papel central en la estética de la recepción; con él, Jauss ejemplifica el principio gadameriano de que el progreso hermenéutico depende de una tensión constante entre el horizonte presente y el texto del pasado. Como en Gadamer, en Jauss el horizonte del presente está siempre en formación en la medida en que es preciso constantemente poner a prueba en él nuestros prejuicios. Este poner a prueba revela la importancia del encuentro con la tradición de la que formamos parte.

Siguiendo siempre a Gadamer, Jauss entiende la comprensión como fusión de horizontes y distancia temporal. Ahora bien, Gadamer piensa que para comprender las obras clásicas no es necesario superar esa distancia que nos separa de ellas, porque ejercen por sí mismas y constantemente la mediación por la que se supera dicha distancia. Jauss considera que esta tesis olvida la relación entre pregunta y respuesta a partir de la cual se constituye toda tradición histórica y relega al receptor a la pasividad. Frente a Gadamer, Jauss opina que el clasicismo de una obra no es innato a la misma, sino que se pone a prueba en cada momento y, por tanto, debe ser capaz de mantener la lógica de la pregunta $y$ la respuesta en el presente.

Gadamer cree, en efecto, que el texto clásico habla a cada época como si se dirigiera a ella en particular y, gracias a su carácter clásico, la obra se significa e interpreta a sí misma. Jauss le reprocha este concepto de clasicismo, heredado de Hegel, porque contradice el principio de la historia eficiente, según la cual comprender no es una simple actividad reproductiva, sino también productiva. Lo clásico, según Gadamer, se sustrae a los cambios temporales, es eterno, en el sentido de que es contemporáneo con todo presente, es lo que se conserva del pasado como no pasado, lo que posibilita el conocimiento histórico. Jauss piensa que ni siquiera lo clásico puede prescindir de la distancia temporal, ya que es necesario interpretarlo salvando la tensión de su enfrentamiento con nosotros mismos. Si Gadamer afirma que son las obras clásicas las que aseguran la mediación a través de la distancia temporal, Jauss piensa que esta tesis es fruto de la concepción platonizante y sustancialista de la obra clásica, según la cual, gracias al poder mimético de ésta, los hombres serían capaces en cualquier tiempo de reconocerse en la obra. Gadamer parece comprender la mímesis como reconocimiento y su concepción del valor cognitivo del arte sigue el esquema pla- 
tónico. En efecto, se ha dicho que Gadamer recae en un platonismo que ha sido superado por la concepción moderna del arte. Sin embargo, como ya hemos visto, la teoría del reconocimiento, en la que se basa toda representación mimética, no es, en Gadamer, sino una señal para entender correctamente la exigencia del ser de la representación artística. La estética ontológica de Gadamer también está guiada por el concepto de mímesis de Aristóteles y, por ello, se orienta hacia la dimensión de lo posible y hacia la crítica de lo real.

Como Gadamer, Jauss analiza en la historia del arte y en la literatura la dialéctica de la pregunta y la respuesta que da nacimiento a la tradición. Considera, sin embargo, que la interpretación no se reduce a una respuesta que dependa del intérprete, porque la tradición literaria es algo más que una serie de proyecciones subjetivas sobre las obras. En la historia de la interpretación de una obra están implícitas la respuesta y la pregunta; es decir, hay un diálogo entre efecto y recepción, entre sujeto del presente y discurso del pasado y, de nuevo siguiendo a Gadamer, la obra dice algo cuando el sujeto actual descubre la respuesta contenida implícitamente en el discurso pasado y la percibe como respuesta a una pregunta que él mismo se formula. En este sentido, la historia no dice nada, únicamente responde. La recepción implica una interrogación que va del lector al texto; no tiene pues sentido el sustancialismo, no hay cuestiones eternas cuya validez sea intemporal, ya que el arte implica la virtualidad del sentido. Para la estética de la recepción, la interpretación configura el valor artístico de una obra y cuantas más interpretaciones sugiera, mayor será su valor artístico. Un texto literario u obra de arte sólo pueden considerarse como tal cuando encuentran lectores, pues de lo contrario se convierten en algo muerto. La estética de la recepción no proclama, sin embargo, que todos los textos ofrezcan posibilidades ilimitadas de interpretación, sino que supone que nuestra comprensión actual del arte evoluciona en el interior de ciertos límites que se pueden conocer, a condición de aclarar primero nuestra precomprensión.

Jauss piensa que el arte no es sólo conocimiento reproductivo de la realidad, sino también prefiguración de experiencias futuras o acciones aún no experimentadas. En su opinión, Gadamer ignora esta dimensión virtual del sentido e hipostasia la tradición ${ }^{12}$. Según Jauss, esto significa que Gadamer reduce el factor de creatividad del acto de comprender y, consiguientemente, sacrifica el aspecto dialéctico de la relación entre producción y recepción y la sucesión, siem-

12 Cfr. ibid., p. 62. 
pre inacabada, de los lectores; Jauss está convencido de que una obra no sobrevive a la tradición ni por las cuestiones eternas ni por las respuestas permanentes, sino en razón de la tensión abierta entre pregunta y respuesta que puede apelar a una comprehensión nueva y a un fructífero diálogo del presente con el pasado ${ }^{13}$. Jauss no ha comprendido que Gadamer se pregunta, siguiendo la antigua práctica fenomenológica, qué es lo que hace que el arte sea arte hoy y mañana, cómo la obra de arte conquista su vida entre el creador y el receptor. De esta manera, desvirtúa la falsa alternativa entre producción y recepción, entre estética de la producción y estética de la recepción. «La lectura es hasta la fecha la forma auténtica y representativa en que es palpable la participación del receptor en el arte. En realidad ocurre lo mismo en todas las artes, que sólo en el reconocimiento encuentran su realización plena, pero esto se manifiesta en la poesía con una diferenciación peculiar» ${ }^{14}$. El artista actual tiene que luchar contra la marea que embota la sensibilidad y, por eso, ofrece excentricidades para que su obra nos persuada. Gadamer comprende, entonces, que el pluralismo de la experimentación es inevitable en la actualidad, porque hay que incorporar arte a la existencia fragmentada $y$, mientras los seres humanos conformen su vida, no se producirá el tan cacareado fin del arte.

Gadamer y Jauss están de acuerdo en que en el arte opera la tradición, pero no como un proceso autónomo, ya que implica una selección por la que los efectos del arte pasado se hacen reconocibles en la recepción presente. La estética de la recepción reivindica la prioridad hermenéutica del arte frente a la función productiva y a la representativa. Con el interés por el efecto y la acogida de la obra, la estética de la recepción se considera superadora de las formas tradicionales de la estética de la producción y la descripción, acusadas de sustancialismo. Así pretende promover un diálogo sobre cómo puede el arte recuperar la función comunicativa, casi perdida. Esta estética no toma al lector como individuo aislado, sino como un participante en el proceso de comunicación en el que las ficciones artísticas también intervienen en la génesis y transmisión del comportamiento social. Por eso creemos que la estética de la recepción debería estudiar la función de creación social del arte y formularla en un sistema de normas y horizontes de expectativas, ya que, a diferencia de la generalidad del concepto gadameriano de «horizonte», el término de Jauss de «horizonte de expec-

13 Cfr. ibid., p. 114.

14 Gadamer, H. G., Das Erbe Europas, Frankfurt a M., Suhrkamp, 1989. Trad. esp. de P. Giralt, La herencia de Europa, Barcelona, Península, 1990, p. 80. 
tativas» tiene la desventaja de haber sido desarrollado tan sólo en el campo de la literatura.

Por su parte, Jauss cree que para superar el sustancialismo de la hermenéutica, es necesario un método. Como Gadamer, critica el ideal del objetivismo, pero desarrolla en su concepto de "horizonte de expectativas" métodos de objetivación y de reconstrucción con alcance empírico y analítico; así pretende describir sistemáticamente los fenómenos de recepción. Como Habermas, Jauss cree que la crítica gadameriana de una comprensión falsamente objetiva no debe sin embargo conducir a la suspensión del distanciamiento metódico del objeto, porque éste es lo que distingue la comprensión reflexiva de la experiencia comunicativa diaria.

Ni Gadamer ni Jauss pretenden justificar cualquier recepción por el simple hecho de ser despliegues de un potencial de sentido ya dado; hay que confiar con Gadamer en la fuerza de la palabra de la obra y en la correcta escucha del receptor o bien, contra Gadamer, hay que hablar no de una fusión controlada de horizontes, sino de fusiones concretas de horizontes y de análisis objetivos de los mismos. El «horizonte de expectativas» de Jauss anuncia esta última consecuencia. Se trata de una interacción entre el horizonte fijo (el de la obra) y un horizonte variable (el del lector): cuando éste entiende el texto, actualiza su significado potencial, a condición de introducir su comprensión previa del mundo en el marco del texto. El concepto de "horizonte de expectativas" subsume los sistemas codificados en la misma obra (fijos) con los horizontes mundanos de expectativas de la praxis vital de los lectores (variables). La estética de la recepción, siguiendo a Gadamer, considera que la significación buscada en la lectura está condicionada por el texto, pero de tal modo que permite que sea el lector quien la produzca.

La semiótica nos enseña que la falta de un elemento en un sistema es significativa; el hecho de que la intención de los textos literarios no se formule expresamente, su indeterminación, permite que la intención del texto se halle en el lector. Puesto que el texto literario no tiene su realidad en el mundo de los objetos, sino en la imaginación de los lectores, tiene la ventaja de que puede contradecir su historicidad, es decir, permitir al lector insertarse ilimitadamente en los acontecimientos que narra. La indeterminación del texto posibilita que el lector convierta la experiencia ajena en privada y esto sucede gracias a la generación de significados en el acto de la lectura. Ahora bien, puesto que en $\mathrm{Ga}$ damer, el texto eminente o literario es el texto escrito (sea histórico, de ficción, 
literario, científico, etc) su característica principal no sería esa indeterminación o esos lugares vacíos, sino la exigencia de interpretación reflexiva.

A pesar de sus puntualizaciones, Jauss aprueba la mayor parte de los presupuestos de la hermenéutica gadameriana: su crítica del objetivismo y de la metodología, la lógica hermenéutica de la cuestión y la respuesta, el carácter interpretativo de la obra de arte (tanto en lo que respecta a su elaboración, como a su lectura), la actividad productiva (no sólo reproductiva) del intérprete, etc. Ahora bien, la interpretación no reduce la estructura de la obra de arte a un simple efecto de su recepción, ya que es una estructura dinámica que sólo puede ser captada en sus concreciones históricas sucesivas. Efecto es el elemento determinado por el texto; recepción el elemento determinado por el destinatario en la concreción o formación de la tradición. Ambos se articulan en un diálogo entre un sujeto presente y un discurso pasado.

Jauss considera que el concepto gadameriano de Wirkungsgeschichte incluye un contrasentido, ya que aprehende el efecto de la obra de arte como si se constituyera unilateralmente en ella misma. Para evitar esto, Jauss distingue entre el efecto de la tradición (Wirkung) determinado por la obra, y la recepción dependiente del destinatario activo y libre que juzga según las normas estéticas de su tiempo y modifica los términos del diálogo ${ }^{15}$. La estética de la recepción reconoce el carácter parcial o la autonomía relativa del arte. Por eso contribuye a hacer comprender la relación entre arte y sociedad o entre producción, consumo y comunicación.

La estética gadameriana y la estética de la recepción son herederas de la teoría fenomenológica del arte. De ahí que algunos representantes de aquélla, como R. Ingarden, hayan contrapuesto a la estructura de la obra literaria los modos de su concreción. Recurriendo a la doctrina de la intencionalidad, Ingarden, afirma que la obra literaria posee dos polos irreductibles: el artístico (texto creado por el autor) y el polo estético (concreción realizada por el lector). Ingarden dice que la obra de arte es la constitución del texto en la conciencia del lector y emplea el término "constitución" en el más puro estilo husserliano de donación del sentido. La obra logra comunicar algo gracias a una dialéctica entre lo que muestra y lo que calla (resuena aquí la tesis husserliana de que toda presentación implica determinadas apresentaciones y despresentificaciones). La lectura manifiesta la inagotabilidad del texto que, a su vez, es condición de

15 Cfr. Jauss, H. R., Pour une esthetrique de la reception, pp. 246 y 259. 
la selección que hace posible la constitución del objeto imaginario. Retenciones y protenciones del lector llenan los espacios vacíos del texto y actualizan sus diferentes lecturas y significados. En estas últimas se constituye el verdadero sentido del texto, porque descubren lo no formulado y lo llenan con los actos representativos del lector, que nos ponen de manifiesto a nosotros mismos.

\section{Conclusión}

La estética gadameriana no es ni una estética simplemente fenomenológica, ni una estética de la recepción sin más. En realidad, la concepción hermenéutica del arte es más englobante, más dialéctica. Gadamer va más allá de la estética literaria de la recepción. Sólo ve en la teoría de la literatura la prolongación de sus pensamientos acerca de la práctica hermenéutica. El lugar por excelencia de la hermenéutica es el juego del lenguaje y del arte. Con el concepto de Weltliteratur, es decir, con la consideración de toda tradición linguística como obra de arte literaria, la estética de Gadamer se extiende a toda posible manifestación linguística de la existencia. Por tanto, el presupuesto de fondo de todo el discurso gadameriano es la omnipresencia y omnipotencia del lenguaje y éste se aprende como un juego de intercambios y como dialéctica pregunta-respuesta. Lo constitutivo del lenguaje del arte es que la obra habla en la comprehensión propia que, gracias a la presencia, cada uno tiene de sí mismo. La presencia hace que la obra de arte se transforme en lenguaje. La obra de arte es una presencia absoluta para todo presente y, al mismo tiempo, su palabra está a disposición del futuro. Lo que nos descubre no es solamente el ser, sino también el deber ser, la necesidad de cambiar nuestra vida. Por eso podemos decir que, en comparación con otros tipos de tradición, la obra de arte es una presencia absoluta para todo presente y, a la vez, guarda su palabra a disposición de todo futuro: «la familiaridad con la que una obra de arte nos afecta es, al mismo tiempo, de manera enigmática, el estremecimiento y el derrumbamiento de lo habitual. No sólo nos descubre el «Tú eres estom, sino que también nos muestra un pavor gozoso y terrible, nos dice también, "Tú debes cambiar tu vida» ${ }^{16}$. Mientras el arte, justamente por su libertad imaginativa frente a lo fáctico, eleva el ser a la verdad, las ciencias empíricas se atan a lo fáctico, ya que por su na-

16 Cfr. Gadamer, H. G., "Aesthetik und Hermeneutik», Kleine Schriften, II, Tübingen, Mohr, 1967. Trad esp. de A. Gómez, en Estética y Hermenéutica, op. cit., p. 62. 
turaleza están destinadas al dominio técnico de lo que se presenta intramundanamente y fracasan cuando intentan explicar el ser de cualquier fenómeno. El arte, en cambio, reposa en la representación de la imaginación y no en la inmediatez del sensible dado; pretende una verdad propia, en la medida en que el libre juego de la imaginación alcanza el conocimiento.

La literatura, según Gadamer, no depende tan sólo de la recepción. Sólo puede comprenderse ontológicamente, como el proceso en el que algo viene a ser en la representación y no como la experiencia estética del lector, ya que la obra no es una conciencia, sino un mundo, por eso la literatura y la filosofía se entrecruzan constantemente. Entre todas las manifestaciones del lenguaje, la obra de arte literaria es, según Gadamer, la que posee una relación privilegiada con la interpretación y, en ese sentido, se acerca a la filosofía. Esta relación especial se produce gracias a que la obra es una realidad subjetivo-objetiva. Su desvelamiento no se logra, por tanto, ni en las estéticas subjetivistas ni en las objetivistas.

Gadamer observa que el artista mira el resultado de su actividad como cumplimiento de una esperanza, en tanto que el receptor atribuye a la obra o al artista una intención o idea. Estas anticipaciones difieren, sin embargo, de la realidad verdadera. La obra es algo logrado y bien terminado, pero no es la simple consecución de un resultado planeado, ni la idea que el receptor reconoce reivindicar. La obra es como un juego o un diálogo auténtico en el que interviene lo imprevisto a la hora de dirigir el progreso de la acción o la conversación. $\mathrm{El}$ arte es símbolo y la esencia de éste; como el juego, no está referido a un fin con un significado intelectual, sino que detenta en sí mismo su significado. El juego es siempre autorrepresentación; del mismo modo, al representarse en el arte, todo ente experimenta un crecimiento en el ser. Todo arte exige un trabajo de reconstrucción, pero esto no basta. Como supo ver Hegel, la esencia del espíritu histórico no consiste en la restitución del pasado, sino en la mediación del pensamiento con la vida actual. Esta mediación del pensar no es una relación externa y posterior al mismo; preserva las diferencias y hace que el pasado exista sólo como presente y como representado.

En definitiva, la experiencia de lo bello no sólo nos transmite algo, sino que produce una intensificación de nuestro sentimiento de conjunto de la vida: «en la obra de arte no sólo se remite a algo, sino que en ella está propiamente aquello a lo que se remite. Con otras palabras, la obra de arte significa un crecimiento en el ser. Esto es lo que la distingue de todas las realizaciones producti- 
vas humanas en la artesanía y en la técnica, en las cuales se desarrollan los aparatos y las instalaciones de nuestra vida económica práctica. Lo propio de ellos es, claramente, que cada pieza que hacemos sirve únicamente como medio y como herramienta. Al adquirir un objeto doméstico práctico no decimos de él que es una 'obra'. Es un artículo. Lo propio de él es que su producción puede repetirse, que el aparato puede básicamente sustituirse por otro en la función para la que está pensado. Por el contrario la obra de arte es irremplazable y lo sigue siendo en la época de su reproductibilidad" 17 . Esto se debe a que la esencia de lo bello es la indiferencia entre lo representado y lo que se representa. La belleza cancela las diferencias entre el ser y sus manifestaciones, es decir, su ser se identifica con el movimiento por el que se manifiesta en lo sensible, no supone separación entre éste y aquél, entre sujeto y objeto. Esto se logra cuando el hombre juega.

No cabe duda de que el principal efecto que la hermenéutica filosófica ha producido en la estética ha sido la recuperación del alcance de verdad del arte. Si el conocimiento es un momento del ser mismo y no una actividad del sujeto, el arte ya no puede entenderse como actividad sublimada, sino justamente como la verdadera actividad humana, como la forma de reconocimiento que profundiza en nuestro autoconocimiento y en nuestro conocimiento del mundo; además tiene una función crítica porque exige que cambiemos nuestra vida. Si la representación es evento en el que se manifiesta el ser, todo arte será la verdad de lo real transmutado en forma, en cuyo conocimiento participamos.

Esta vinculación del arte con la verdad ha llevado a Gadamer a anunciar que la estética ya no puede ser reflexión sobre las puras condiciones transcendentales de posibilidad de la experiencia del arte y de la belleza, sino que ha de ser escucha de la verdad que se abre en las obras. Pero, ¿cómo escucharla? No se trata de extraer verdades enunciativas, sino más bien de transformar a quien está implicado en la experiencia artística. Lo que Gadamer no ha concretado es el carácter que debe tener esta transformación y, por eso, parece que toda modificación (sea del signo que sea) tenga que aceptarse.

Se ha dicho, en este sentido, que Gadamer no ofrece criterios para discriminar las obras de arte que aumentan nuestra comprensión de las que no lo hacen, pero su concepción sugiere que una obra de arte falsa, Kitsch, es aquella

17 Gadamer, H. G., Die Aktualität des Schönen, Stuttgart, Reclam, 1977. Trad. esp. de A. Gómez, La actualidad de lo bello, Barcelona, Paidos, 1991, pp. 91-92. 
que pretende ser completa conciliación de contenido y forma, modelo acabado. Lo que cuenta no es que la obra sea verdadera, sino que sea una totalidad de significado, independientemente de que la encontremos en el escenario o en la vida cotidiana. La carencia de normas estéticas en Gadamer conduce, por otra parte, a la comprensión de la obra de arte como testimonio histórico, parangonable a otros. Esta tesis choca con el énfasis moderno en el arte y en el artista, que ha desembocado en una estética para minorías (cuasiafásica) y en una paralela estética del Kitsch para las masas. Contrariamente, la estética inspirada en la hermenéutica presta más atención a la existencia social del arte y a la recepción de ésta.

La crítica de la idea de verdad como conformidad ha llevado a la hermenéutica a concebir la verdad con el modelo del habitar y de la experiencia estética, pero dicha experiencia tiende a presentarse con la imagen de la integración armoniosa; esta tendencia corre el riesgo de desembocar en un fundamentalismo que identifique la apertura con la bruta factualidad de una forma de vida indiscutible, que sólo se muestra en su vigencia como horizonte de todo posible juicio. Por supuesto que también puede conducir a otras alternativas distintas, concretamente a un distanciamiento del énfasis que la modernidad ha puesto en la certeza y en la subjetivación de la verdad. La hermenéutica nos invita, por tanto, a elegir. Nos enseña que la estética ya no puede ser reflexión sobre las condiciones transcendentales de posibilidad de la experiencia del arte y de lo bello, sino que ha de ser escucha de la verdad que se abre en las obras. Pero, ¿cómo se realizará la escucha? Gadamer sólo nos dice que participando en su mensaje, recibiendo la interpretación como un incremento del ser, transformándonos, pero no dice de qué modo o en qué dirección. Nos anima a leer la obra de arte como testimonio histórico, pero no nos dice si es algo más o si su ser se agota en manifestar nuestro tiempo. El hecho de que Gadamer otorgue tal importancia al arte así parece confirmarlo. Recordemos que, para él, el arte es un modo de interpretación privilegiado, porque plasma la verdad hacia la que debemos tender, la aplicación en el presente de la llamada que proviene del pasado. 